NOTAS 


\title{
TRASCENDENCIA TERRITORIAL DEL PUERTO DE CARTAGENA
}

\author{
Alfredo Morales Gil \\ Departamento de Análisis Geográfico Regional \\ Universidad de Alicante
}

RESUMEN

El análisis de las infraestructuras viales constituye un objetivo básico del estudio de cualquier organización territorial. En este sentido, el puerto de Cartagena ha desempeñado un papel vertebrador para el sureste y centro peninsular ibérico. Dos han sido y son las condiciones que lo hicieron posible: de un lado, sus buenas dársenas naturales y de otro, su proximidad a la gran ruta marítima, que desde el Estrecho de Gibraltar se dirige a Extremo Oriente por el Canal de Suez.

Palabras clave: Ordenación territorial, infraestructuras, articulación portuaria.

\begin{abstract}
The analysis of the road infrastructures constitutes a basic aim about any territorial organization study. Whith regard on the subject under discussion, the port of Cartagena has played a role to provide the backbone of territory for the south-east and Iberian Peninsular center. The conditions that made it posible have been and continue being two: its good natural docks and its proximity to the maritime route, which goes from Strait of Gibraltar to Far East across Suez Canal.
\end{abstract}

Key words: Land management, infrastructures and port joint.

\section{Las bases de integración territorial}

En este principio de siglo XXI, en que se está planificando el desarrollo socioeconómico regional murciano en el contexto de la UE, debe ocupar un lugar destacado el estudio de las redes estructurantes de los transportes básicos para estas tierras, a fin de poder ofrecer unas condiciones óptimas para las distintas formas productivas regionales. Por estas razo- 
nes, hay que pensar que las redes viarias del transporte han de adaptarse a las exigencias que aquéllas tienen para su mejor implantación y desarrollo.

La Región de Murcia para mantener tanto su modelo económico tradicional, basado en la vocación exportadora de la agroindustria y de las frutas y hortalizas frescas, así como por la necesidad de importaciones de materias primas para atender las demandas de otras actividades y, muy particularmente, la difusión de otras nuevas mediante la habilitación de espacios industriales o de turismo y ocio, tiene, como condición básica, el disponer de un magnífico sistema de redes viarias.

A su condición física periférica, en el conjunto de España mucho más respecto a la Unión Europea, ha unido históricamente el agravante de que sus deficientes comunicaciones exteriores la han aislado más de lo que la propia naturaleza imponía. En la actualidad, se están superando gran parte de esas carencias seculares en sus relaciones exteriores, a la vez que se avanza rápidamente en su vertebración interior.

Hay un consenso generalizado sobre el papel estructurante que desempeñan las infraestructuras en la dinámica del desarrollo regional, por lo que resultan más atractivas para la inversión privada aquellas regiones mejor dotadas. Su efectividad se traduce en factor impulsor del crecimiento socioeconómico. Consiguientemente, invertir en ellas es la política más utilizada por los gobiernos para estimular el desarrollo y, en algunos casos, atenuar los desequilibrios espaciales, ya que llegan a constituir un factor básico para potenciar las actividades económicas y reforzar las estructuras de promoción y de competencia, y de las actividades sociales, desde el punto de vista de la mejora de las condiciones de vida. Es por ello que los economistas han definido el término infraestructura como «aquella parte del capital global de las economías locales, regionales o estatales que, debido a su carácter público, normalmente no es suministrado por el mercado, por lo que su provisión queda fundamentalmente confiada a las administraciones públicas (BIEHL, 1988).

La dotación de infraestructuras viales es al mismo tiempo causa y consecuencia del nivel general de desarrollo económico. Por ello, según las circunstancias, puede afirmarse que éstas, por un lado, sirvan de impulso inicial y, por otro, deben de cubrir las demandas derivadas de su evolución. Ha sido el segundo caso el experimentado en tierras murcianas.

De acuerdo con el enfoque de planificación potencial de cada una de las modalidades de transporte, las infraestructuras viales van a constituir el factor básico de desarrollo regional o comarcal. De él van a estar pendientes las diferentes estrategias del capital a la hora de ultimar sus asentamientos productivos. Así, las regiones subequipadas tienden a infrautilizar su potencial de desarrollo y a convertirse paulatinamente en periferias de los sistemas. El caso murciano se encuentra en una situación crítica y difícil, dependiente de la capacidad de su gobierno regional para con la ayuda de la administración central y de la UE, superar esa posición de ruptura o fractura que en 1992 señalaba Gaudemar en el extremo SW. del Arco Mediterráneo, dentro del modelo de articulación de infraestructuras, previsto para las décadas venideras en la Unión Europea. Su superación se materializará si las redes viarias del mencionado arco, sobre todo las ferroviarias y portuarias, son desarrolladas a corto plazo para hacer de eslabón de unión entre las comunidades de Valencia y Andalucía.

En efecto, el planeamiento de las redes viales de la Región de Murcia debe de hacerse desde dos perspectivas, que en realidad son complementarias: exterior (accesibilidad a la región) e interior (articulación de su territorio). Para la primera se tiene que actuar en la búsqueda sus relaciones peninsulares y del espacio físico de toda la UE, sin olvidar su posición estratégica respecto a la ruta marítima de Oriente-Occidente por el Canal de Suez y el Mediterráneo, materializada en la presencia del puerto de Cartagena.

$\mathrm{Si}$ es cierto, que desde hace medio siglo, han proliferado toda una serie de estudios y formulaciones teóricas, que pretenden analizar los distintos espacios o áreas territoriales 
murcianas, a fin de definir el modelo de infraestructuras viarias más apropiado desde una perspectiva económica, no es menos cierto que sus resultados son necesariamente simplificadores, ya que se basan en la síntesis de un gran número de variables cuantificadoras en las que no están presentes los condicionantes orográficos, climáticos, hidrológicos, etc. que determinan su validez de explicar, de forma simple y gráfica, unos procesos territoriales de gran complejidad. En el caso murciano se hace necesario tener un conocimiento previo de la estructuración de sus relieves, que son los definidores de las directrices básicas de sus diferentes áreas productivas y de asentamientos poblacionales, que a su vez delimitan el desarrollo de una malla básica vial terrestre y la ubicación de las principales instalaciones portuarias costeras. Así, los paroxismos alpinos provocaron recortes en los relieves costeros, con apertura de bahías perfectamente abrigadas y protegidas de los vientos dominantes en el Mediterráneo occidental, que se han utilizado para las instalaciones de Cartagena, Escombreras y Águilas.

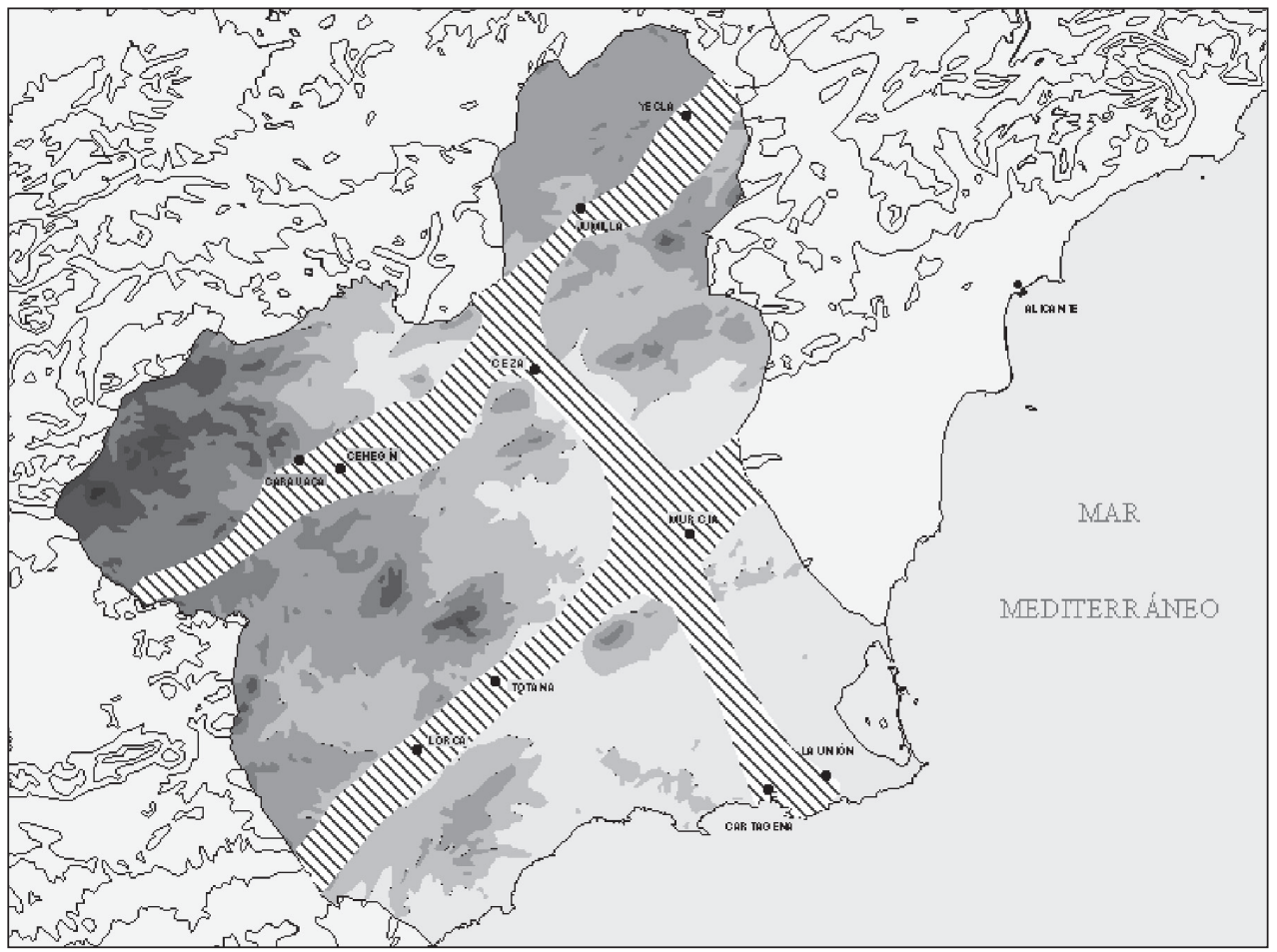

Figura 1. Caminos naturales de la Región de Murcia.

La falla transversal a los dos pasillos naturales, Fosa Intrabética y valles corredores subbéticos, está ocupada por el río Segura en su parte septentrional, y actúa comunicándolos al tiempo que facilita sus relaciones por el norte con La Mancha y por el sur con el Mediterráneo. En este último extremo se localiza la bahía de Cartagena. Esta ruta llamada antiguamente de la Seda, se reforzó en el siglo XIX con la construcción del ferrocarril de Madrid lo que determinó una revaloración de sus instalaciones portuarias, que vieron incrementarse el dinamismo sobre ellas por el intercambio con su traspaís y las actividades mineras y petroquímicas ubicadas en sus inmediaciones. Este proceso duró hasta la década 
de los setenta del siglo pasado en que entró en un período de atonía del que se intenta recuperar en la actualidad.

Las redes viarias del transporte han de adaptarse a las necesidades que las formas productivas actuales demandan y a las previstas en las futuras planificaciones territoriales. Ahora bien, cualquier decantación por un modo de transporte u otro, se debe hacer considerando las características de éstos en relación a los fines perseguidos y teniendo presente las flexibilidades que cada uno de ellos ofrece. Por ello es necesario recordar: $1^{\circ}$ que para movilizar grandes volúmenes de materias primas y productos manufacturados a larga distancia el modo más económico es el transporte marítimo y fluvial, por su escaso coste por unidad desplazada, se encuentra por ello en el origen y final de los procesos de fabricación; $2^{\circ}$ el ferrocarril se adapta a la evacuación de todas las mercancías no perecederas en distancias superiores a los $300 \mathrm{Km}$ y a los desplazamientos de viajeros en las redes de cercanías y en trayectos de 300 a $1.000 \mathrm{Km}$ en los de altas velocidades; 3o el avión resulta útil para los movimientos de individuos y de mercancías de alto valor unitario en distancias de más de $1.000 \mathrm{Km}$, o incluso de hasta $500 \mathrm{~km}$, siempre que no exista entre destinos una vía terrestre rápida, y $4^{\circ}$ la carretera ha tenido y presenta de cara al futuro unas buenas posibilidades en la vertebración interior de un territorio como el de la Región de Murcia y para la exterioridad de sus producciones hortofrutícolas en sus destinos peninsulares y de la Unión Europea.

De lo anteriormente expuesto, se deduce, que la Región de Murcia debe apostar por el transporte de mercancías voluminosas y de bajo coste unitario, el marítimo, de cara al exterior, y el ferroviario para el peninsular. La carretera se utilizará, por su mayor flexibilidad, a fin de atender a sus relaciones internas y su enlace con los puntos de ruptura de carga en las interconexiones modales y para dar salida a toda la producción hortofrutícola en fresco. Consecuentemente, se puede afirmar que buena parte del crecimiento socioeconómico regional futuro va a depender del desarrollo y mejora de las instalaciones portuarias cartageneras y de las redes viarias terrestres convergentes sobre él.

\section{Organización y funcionalidad portuaria}

En el territorio murciano va a ser, sin lugar a dudas, el puerto natural cartagenero la pieza clave del desarrollo de la red de caminos que lo cruzan con direcciones NE, N y SW. Y que, lógicamente, convergían en él. Tanto los arqueólogos como los historiadores coinciden en afirmar que sus buenas condiciones naturales favorecían el que todos los pueblos, que desde el II milenio antes de Cristo, comerciaron por el Mediterráneo Occidental, lo utilizaron para realizar una escala obligada en sus relaciones con las tribus argáricos e ibéricos. Si bien, fueron los cartagineses de los que primero se tienen noticias de que hiciesen un ordenamiento de sus dársenas, que posteriormente en el siglo III a.C. volvieran a revalorizar los romanos, no solo por su posición estratégica, si no que, también, fue apreciado por los yacimientos de minerales metálicos de las sierras próximas (galena argentífera, sobre todo) y el aprovechamiento del esparto.

El tráfago portuario del puerto de Cartagena y su flujo circulatorio terrestre convergente sobre él van a ser los encargados de organizar una red viaria en las direcciones anteriormente indicadas, que actuaron como factor de potencialidad económica y de diversificación social y cultural, que sólo se vio dificultado hacia su interior septentrional por las montañas béticas orientales.

Las instalaciones portuarias han evolucionado a partir de su antigua instalación en el fondo de la rada de Cartagena, extendiéndolas por su función militar y comercial a las inmediatas dársenas de La Algameca y Escombreras. Esta tercera área marítimo-terrestre 


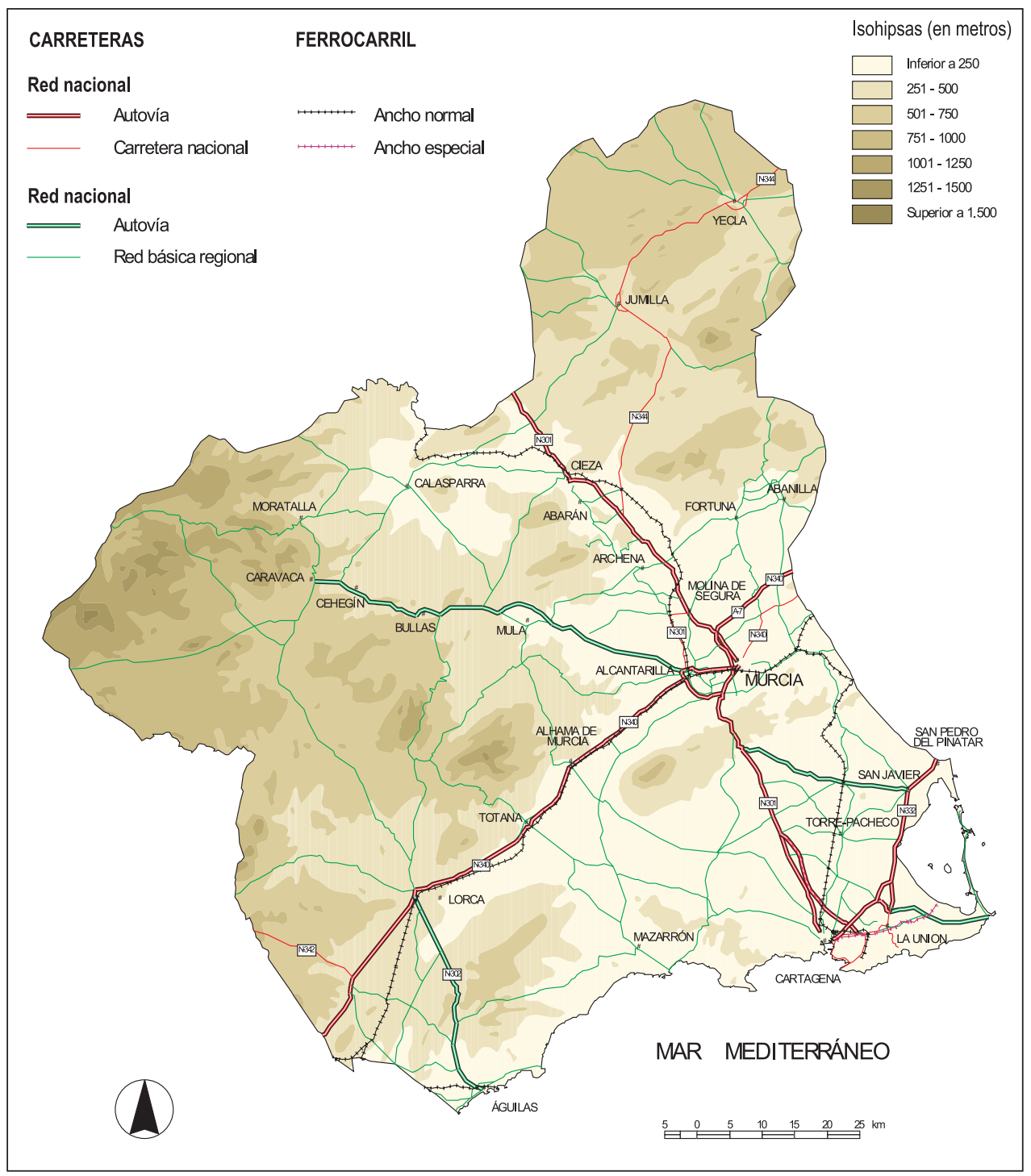

FIGURA 2. Red de ferrocarriles y carreteras principales de la Región de Murcia (2004).

ha sido la que le permitió, desde la década de los años cincuenta del pasado siglo, hacer su gran reconversión, que en la actualidad se está afianzando y desarrollando con gran éxito, en competencia con sus vecinos del litoral mediterráneo español.

El puerto de Cartagena se encuentra situado en los $0^{\circ} 59^{\prime}$ de longitud W y los $37^{\circ} 35^{\text {' }}$ de latitud $\mathrm{N}$, en el Mediterráneo Occidental, frente a la gran ruta marítima mundial de Europa Occidental con los países asiáticos del Océano Índico y del Pacífico Occidental. Se trata de un doble puerto que se beneficia de la existencia de las bahías profundas y con buenos abrigos naturales, estructurados, por los movimientos alpinos, en la zona nororien- 
tal de la Cordillera Bética interior, en la que una falla longitudinal ha recortado el litoral y donde unas fracturas transversales a la primera han delimitado dos dársenas bien resguardadas de los vientos de levante y poniente, lo que las convierten en unas superficies marinas en las que con pocas obras de infraestructuras se consiguen unas magníficas condiciones para la maniobrabilidad en su interior de los grandes barcos que surcan en la actualidad los mares. A ello contribuye, también, la casi inexistencia de temporales marítimos en sus proximidades, que en los casos extremos solo han medido olas máximas en su antepuesto de 6,3 m. y una carrera de marea de no más de $0,70 \mathrm{~m}$.

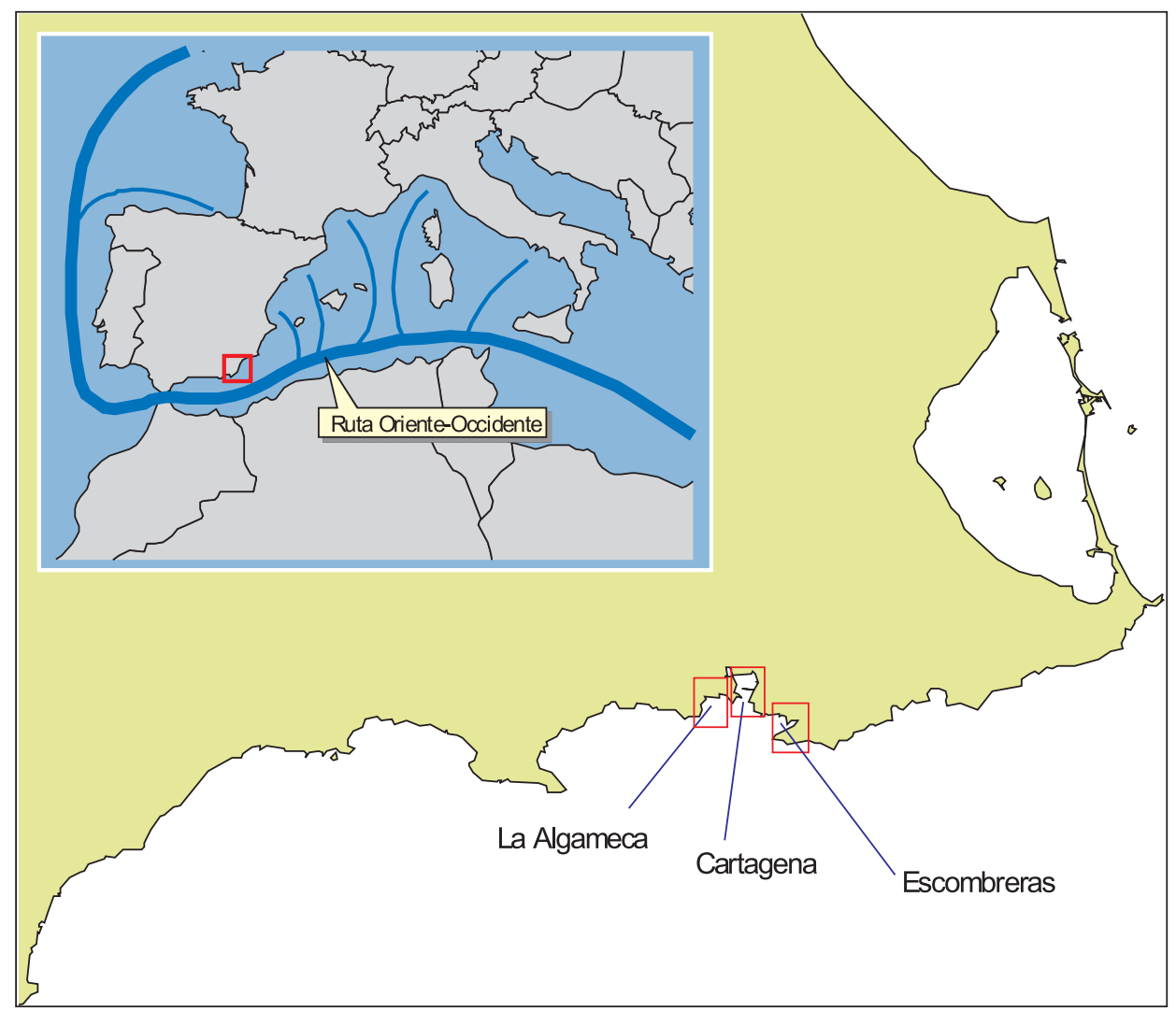

FIGURA 3. Localización de las dársenas de La Algameca, Cartagena y Escombreras y su posicionamiento respecto a las grandes rutas marítimas del Mediterráneo.

El doble puerto cartagenero es, por tanto, el único importante del frente costero del sureste y sur peninsular, excepción hecha de Algeciras. Sus dársenas tienen una superficie de 259,65 ha. y un fondeadero en el antepuerto de 577,70 ha. Sus muelles miden en la actualidad más de 5.000 metros de longitud, con calados de entre 6 y 12 metros en la dársena de Cartagena y de 10 a 21 en la de Escombreras. Estas instalaciones son las que le permitieron en la década de los setenta del siglo XX alcanzar el primer lugar entre los de España, por volumen total de mercancías movidas en ellas.

Este desarrollo tuvo su base en la instalación de la gran refinería de petróleos en la bahía de Escombreras en 1950, destinada a abastecer por cabotaje los puertos mediterrá- 


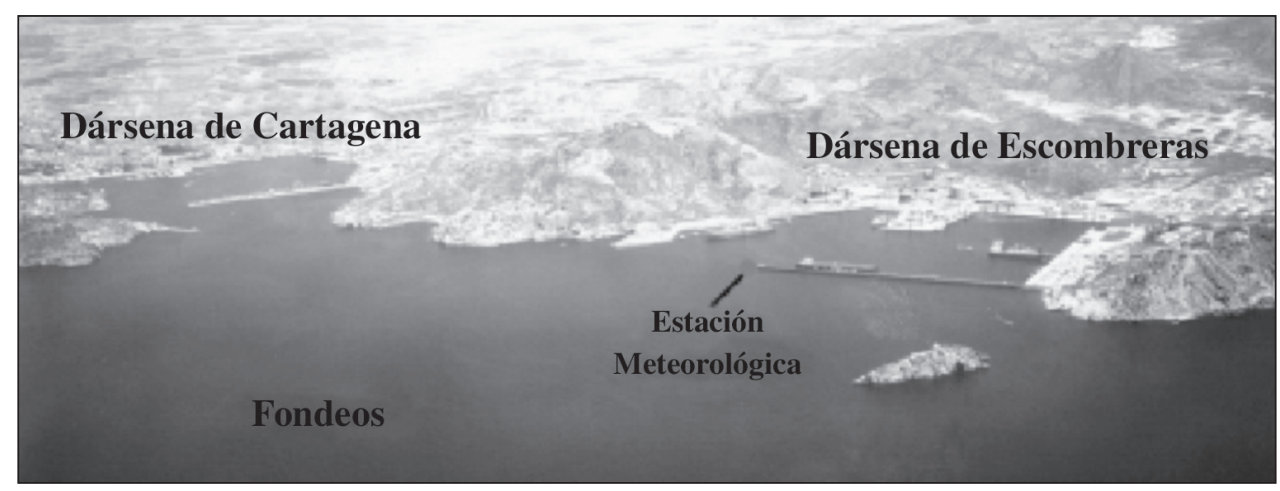

Figura 4. Foto oblicua en la que se aprecia la localización de las dársenas

Fuente: http//www.apc.es. Autoridad Portuaria de Cartagena.

neos españoles y por ferrocarril al centro y cuadrante sureste peninsular. A su amparo en 1957 se instaló una gran central termoeléctrica y posteriormente otras industrias petroquímicas. En la década de los ochenta del pasado siglo, con la construcción del muelle de graneles Príncipe Felipe, de 350 metros de longitud y 16 de calado, se inicia su proceso expansivo actual, que conllevó la instalación de la planta de regasificación de ENAGAS y proyectos de más centrales térmicas, en proceso de construcción ahora. Pero esta actividad portuaria creciente ha exigido la planificación de una ampliación de muelles en esta dársena, que se está construyendo hoy en día y, que supone, la obra de un nuevo dique desde la Punta de los Aquilones hasta las proximidades de la Isla de Escombreras y su proyección hacia el NW, a fin de conseguir una lámina de agua abrigada de dimensiones similares a la existente en la actualidad y un calado de 15 a 20 metros. En su ángulo sursureste se va a rellenar para triplicar la superficie disponible de maniobrabilidad de mercancías. También se construirá un nuevo pantalán que atenderá a la carga y descarga del petróleo y sus derivados. Estas obras se esperan que estén operativas en el año 2007.

El futuro del puerto de Cartagena hay que plantearlo en un contexto nacional y un amplio foreland, para lo que se hace necesario dotarlo de unas infraestructuras complementarias terrestres, entre los que destacan las autopistas A-30 y AP-37, gasoductos y oleoductos, todas ellas ya realizadas y, lo que es más importante, una buena conexión ferroviaria que le permita una relación rápida con su hinterland, sobre todo con el puerto seco de Madrid, y de la que en la actualidad carece. Pues, el viejo ferrocarril decimonónico, no ha sido, todavía, modernizado y con faltas de las más elementales condiciones básicas para un buen funcionamiento, como son doble vía y electrificación. Puerto y ferrocarril son complementarios, si falla uno de ellos se rompe la conjunción de intereses y se produce un retraimiento de la actividad, que ha sido lo sucedido entre 1975 y 2001, en que se ha iniciado otro proceso de recuperación portuaria.

Resulta razonable, por lo señalado anteriormente, que las principales acciones planteadas para su mejora sean las del establecimiento de infraestructuras viarias terrestres que conecten al conjunto ciudad-puerto con la Región de Murcia, Sur de la Comunidad Valenciana, provincias orientales de Andalucía y, básicamente, con Madrid y Castilla-La Mancha. Pues, de él depende, en mayor medida el gran desarrollo socioeconómico del conjunto regional murciano y, en especial del Campo de Cartagena, a los que está dando servicios directamente en la actualidad. Para ello basta recordar la existencia de los oleoductos Cartagena-Puerto de Alicante y Puertollano (Ciudad Real), gasoducto a Orihuela, líneas de alta tensión Escombreras-Granja de Rocamora y la que conecta con la central térmica de Carboneras. 


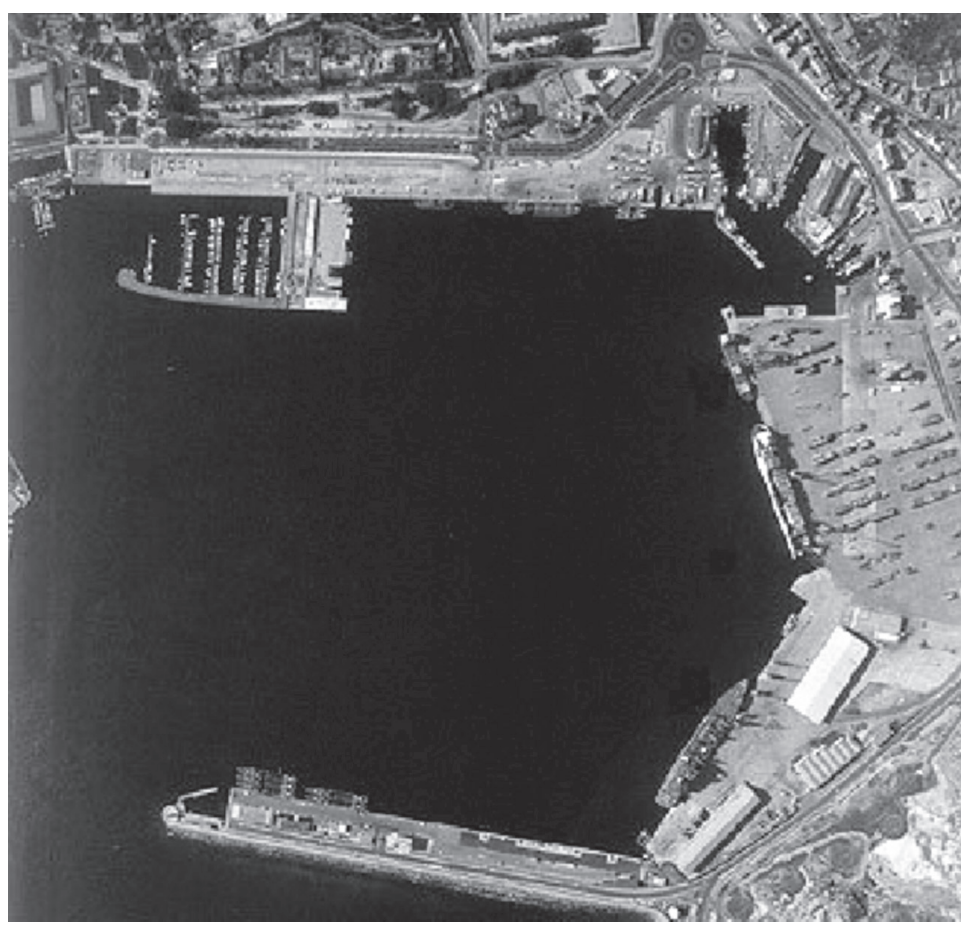

Figura 5. Dársena de Cartagena (2000)

Fuente: http//www.apc.es. Autoridad Portuaria de Cartagena.

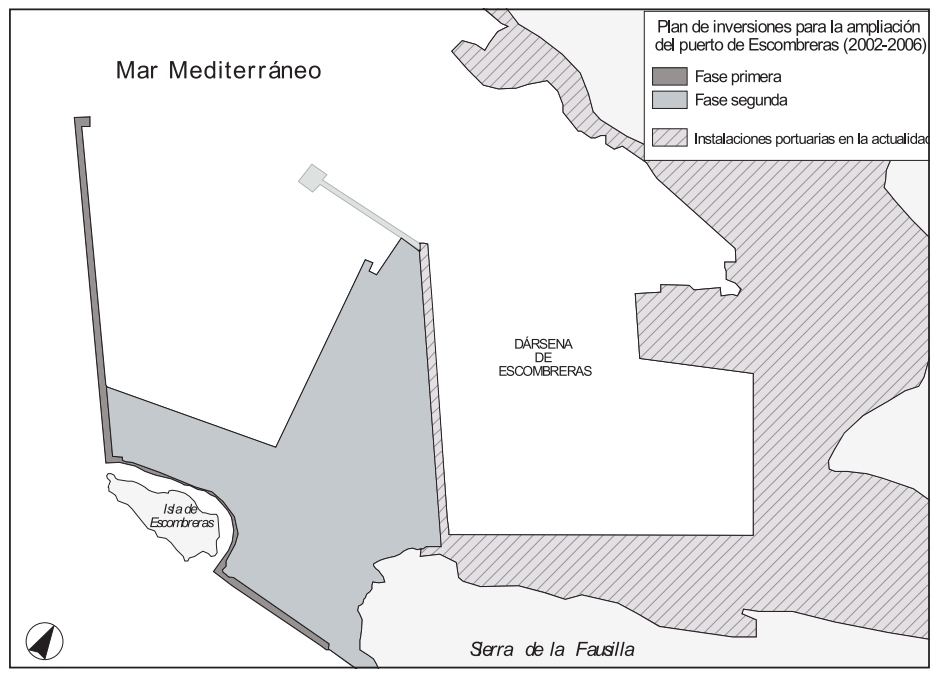

Figura 6. Croquis de las instalaciones actuales de la dársena de Escombreras y su próxima ampliación

Fuente: http//www.apc.es. Autoridad Portuaria de Cartagena. 
Consecuentemente, la infraestructura portuaria cartagenera cumple varias funciones, que a efectos de enumeración se reducen a dos. De un lado, sigue siendo una importante puerta para la entrada de los crudos, gas natural y otras mercancías de ultramar, y en este sentido abarca un espacio marítimo muy amplio articulado entorno a los ejes de comunicación con el Caribe, Golfo Pérsico, Norte de África, a los que hay que sumar la relación con Europa tanto para las entradas (de graneles sólidos, contenedores,...) como para las salidas (producciones agroalimentarias murcianas y regionales de otras vecinas, plásticos, gasolinas y otros). Por otro lado, desempeña funciones de aprovisionamiento y salida de productos para un hinterland bastante restringido ya que, eliminados los hidrocarburos, el $90 \%$ del tráfico tiene sus orígenes y destinos en las comarcas próximas. Así, se explica el escaso engranaje que esta infraestructura marítima mantiene aún con el ferrocarril, como revelan los datos de que más del $75 \%$ de los flujos de entrada y salida en la zona del puerto se efectúen por tubería, un $24 \%$ por carretera y alrededor del $1 \%$ en tren (López Ruiz, 1991).

\section{Evolución del tráfico de mercancías del puerto de Cartagena}

\begin{tabular}{|l|l|}
\hline 1955 & $4.700 .000 \mathrm{Tm}$. \\
\hline 1960 & $8.500 .000 \mathrm{Tm}$. \\
\hline 1965 & $10.354 .000 \mathrm{Tm}$. \\
\hline 1970 & $16.173 .000 \mathrm{Tm}$. \\
\hline 1975 & $14.644 .000 \mathrm{Tm}$. \\
\hline 1980 & $13.767 .000 \mathrm{Tm}$. \\
\hline 1985 & $11.647 .000 \mathrm{Tm}$. \\
\hline 1990 & $13.795 .000 \mathrm{Tm}$. \\
\hline 1995 & $10.919 .000 \mathrm{Tm}$. \\
\hline 1999 & $12.501 .000 \mathrm{Tm}$. \\
\hline 2000 & $13.941 .000 \mathrm{Tm}$. \\
\hline 2001 & $20.371 .521 \mathrm{Tm}$. \\
\hline 2002 & $22.065 .754 \mathrm{Tm}$. \\
\hline 2003 & $21.200 .000 \mathrm{Tm}$. \\
\hline
\end{tabular}

Fuente: http//www.apc.es. Autoridad Portuaria de Cartagena y elaboración propia

Finalmente, hay que señalar que la preocupación reciente de la sociedad por una mejor calidad de vida, con una consideración destacada por los valores medioambientales e histórico-culturales, ha provocado el enfrentamiento entre puerto y ciudad y ha obligado a los planificadores de uno y otro espacio a buscar un modelo de relaciones que permitiera una simbiosis positiva para ambos. En el caso de Cartagena, esta dialéctica se ha hecho patente, con resultados diferentes. Así, la dársena antigua ha cedido espacio a la ciudad y ha sacado de sus muelles toda aquella actividad contaminante, al tiempo que el dique más próximo se ha destinado al atraque de una flota turístico-deportiva. Mientras a la de Escombreras se han desplazado todos aquellos tráfagos de mercancías que representaran, riesgo físico o contaminante para sus habitantes, como ha sido su especialización en carga 
y descarga de productos petrolíferos, gas natural y demás mercancías contaminantes, graneles sólidos químicos, básicamente.

Las infraestructuras portuarias cartageneras en la actualidad, todavía no han sido apreciadas, por los planificadores regionales murcianos, como el elemento básico del sistema de desarrollo territorial, al que debe darse la cohesión que en parte adolece, y se han de pergeñar las líneas básicas para su buen desarrollo. Cierto es que la autoridad portuaria está apostando por esta vía de futuro, al diseñar e iniciar todo el proceso de ampliación de la dársena de Escombreras, pero que no es seguida a igual ritmo desde los poderes regionales y centrales, al no atender con la misma intensidad y celeridad a la mejora y ampliación de la red ferroviaria básica para que ésta se deje sentir en su ampliación de hinterland, que le corresponde en el conjunto de las regiones españolas. Desarrollo del puerto de Cartagena y mejora de la red ferroviaria, en definitiva, tienen que ir de la mano, de lo contrario se está retardando la efectividad de las actuaciones realizadas en el primero.

Si se sigue progresando en la línea indicada, este doble puerto, volvería ocupar el lugar preeminente entre los del Mediterráneo Occidental, tal como vaticinó en 1974 Verlaque, que consideró que solamente en el litoral español existía otra instalación portuaria, por su posición y abrigo de aguas, capaz de superarla, Algeciras. Con ello, la Región Murciana, contaría con otro centro de actividad e inductor de generar riqueza en sus inmediaciones y serviría de atracción de ubicación de industrias manufactureras, que necesitan cierta proximidad a un puerto para recibir materias primas y exportar los productos con bajos costes, como los proporcionados por el transporte marítimo.

\section{Bibliografía}

BIEHL, D. (1988): «Las infraestructuras y el desarrollo regional» en Papeles de economía española, $\mathrm{n}^{\mathrm{o}}$ 35. Madrid, pp. 293-311.

BROTONS YAGÜE, F. y RAMALLO ASENSIO, S.F. (1989): «La Red Romana en Murcia», en Los Caminos de la Región de Murcia. Ed. De A. González Blanco, Ed. Consejería de Política Territorial y Obras Públicas, Murcia, pp. 101-120.

CALVO GARCÍA-TORNEL, F. (1999): «Las infraestructuras de transporte» Región de Murcia. Instituto de Fomento, Murcia, pp. 171-180

CALVO GARCÍA-TORNEL, F. y MORALES GIL, A. (1998): Potencial de captación y generación de tráfico del aeropuerto de Alicante. Editorial Civitas, S.A. Madrid, pp. 374.

GAUDEMAR, J.P. (1992): «Reflexiones prospectivas sobre la evolución económica del Mediterráneo Noroccidental» en Papeles de economía española, $\mathrm{n}^{-}$11. Madrid, pp. 33-71.

LÓPEZ RUIZ, J.M. (1991): «Las infraestructuras de comunicación» en Atlas de la Región de Murcia. Ediciones Prensa Ibérica, S.A. Murcia, pp. 313-336.

MORALES GIL, A. y GIL OLCINA CANTOS, J. (1994): «La red ferroviaria en el sureste peninsular: realidades y propuestas». Papeles de Geografía, no 20. Ed. Universidad de Murcia, pp. 221237.

MORALES GIL, A. (1973): «Las comunicaciones en Murcia ante el desarrollo económico regional» en Papeles del Departamento de Geografía no 5. Universidad de Murcia, pp. 119-156.

- (1989): «Las condiciones naturales y la circulación en la Región de Murcia» en Los caminos de la Región de Murcia. Editorial Consejería de Política Territorial y Obras públicas, Murcia, pp. 29-37.

- (2000): «Articulación regional: redes viarias» en Hacia un nuevo espacio Euromediterráneo. Editorial Universidad de Sevilla, pp. 171-190.

MORALES GIL, A. y OLCINA CANTOS, J. (1994): «La red ferroviaria del sureste peninsular: realidades y propuestas» en Papeles del Departamento de Geografía nº 20. Editorial Universidad de Murcia, pp. 221-237.

ROMERO, J. (2001): La periferia emergente: La Comunidad Valenciana en la Europa de las Regiones. Ed. Ariel, Barcelona, 558 pp. 
SERRANO MARTÍNEZ, J.M. (2001): Los transportes en la Región de Murcia. Editorial Fundación de Estudios Murcianos e Investigaciones Locales R.M. Murcia, pp. 318.

VERA REBOLLO, J.F. (1993): «Las infraestructuras de transporte en el Arco Mediterráneo» en Algunas cuestiones de ordenamiento del territorio. Instituto Universitario de Geografía de Alicante, pp. 67-100. 